\title{
SOBRE LA RECEPCIÓN DE JOSEFO \\ EN LA GENERAL ESTORIA DE ALFONSO X (PRIMERA PARTE)*
}

\author{
Juan Antonio López Férez \\ Universidad Nacional de Educación a Distancia (UNED) (Madrid) \\ jalferez@flog.uned.es
}

\section{RESUMEN}

Los redactores de la Primera Parte de la General Estoria recurrieron con gran frecuencia a la versión latina de las $A I$ (Antiquitates Iudaicae) de Josefo. Nuestro estudio se centra en varios apartados: datos ofrecidos por Josefo, y no por la Biblia, pero recogidos en la $G E$; puntos que la $G E$ atribuye a Josefo pero que en este aparecen de otra manera o, sencillamente, no constan; hechos relatados por Josefo con brevedad pero ampliados consideradamente en la redacción alfonsí; y, por último, algunos errores importantes contenidos en la $G E$, cuando los hechos son descritos de forma distinta en el historiador judío.

Palabras Clave: Antigüedades judías, Josefo, General Estoria.

ON THE RECEPTION OF JOSEPHUS IN THE GENERAL ESTORIA OF ALFONSO X (FIRST PART)

\section{ABSTRACT}

The editors of the First Part of the General Estoria used Josephus' Latin version of the AI (Antiquitates Iudaicae) with great frequency. Our study focuses on some items: data offered by Josephus, and not by the Bible, but collected in the $G E$; points that the $G E$ attributes to Josephus but that appear in another way or simply do not appear; facts related by Josephus briefly but extensively considered in the Alfonsi writing; and, finally, some important errors contained in the $G E$, when the events are described differently in the Jewish historian.

KeYwORDs: Jewish Antiquities, Josephus, General Estoria.

1. Flavio Josefo (37-100 d. C.), nacido en Jerusalén, en el seno de un matrimonio formado por un sacerdote y su esposa procedente de sangre real, dio enseguida muestras de aplicación e inteligencia. Visitó Roma en el año 64 y quedó impresionado por el poder romano. Además de esos datos, el propio autor nos ofrece otros numerosos en su Vida, obra tardía, terminada al final de sus días. Intervino, como intérprete y mediador, al lado de Tito, hijo del emperador Vespasiano y posterior heredero del poder supremo, en la guerra declarada por Roma contra los judíos (conflicto relatado en su Historia de la guerra judaica contra los romanos, en siete libros, publicada en los años 75-79) (en latín, Bellum Iudaicum = BI). El historiador viajó 
a Roma con los vencedores y ya vivió siempre allí gozando de los más altos honores otorgados por los sucesivos emperadores y teniendo a mano para su trabajo las inmensas bibliotecas imperiales. Para la General Estoria de Alfonso X (desde aquí GE) en la parte que nosotros estudiamos, la obra esencial de Josefo es las Antigüedades judías (= Antiquitates Iudaicae = AI), aparecida en los años 93-94, en veinte libros. Abarca sucesos desde la creación del mundo hasta el año 66 y tiene como objetivo engrandecer al pueblo hebreo a los ojos del mundo grecorromano. Con respecto al texto bíblico, Josefo manejó tanto el hebreo-arameo como la versión griega de los Setenta, incorporando no pocos elementos de tradición oral (así, el nacimiento e infancia de Moisés; la campaña de este contra los etíopes, etc.) ${ }^{1}$. Por otro lado, Josefo menciona en ocasiones sus fuentes históricas: Beroso, Manetón, Nicolás de Damasco, etc. La cuarta obra del historiador es Contra Apión (en latín, Contra Apionem = Ap.), aparecida después del 94, donde tenemos una verdadera apología del judaísmo y, además, una exposición general del antisemitismo tal como se produjo en el siglo I. Aparte de su importancia esencial para la historia de los judíos, Josefo ha sido utilizado por numerosos estudiosos de la Biblia, tanto por las similitudes entre ambos conjuntos literarios como por las discrepancias de los mismos. Muy leído desde la publicación de sus obras, la imprenta ayudó a la divulgación de las mismas en toda Europa, especialmente las traducciones latinas, entre las que sobresale la de 1481. Por su lado, la edición princeps del texto griego no vería la luz hasta $1544^{2}$.

2. Josefo fue traducido al latín relativamente pronto ${ }^{3}$. Posiblemente correspondió al círculo de Jerónimo de Estridón la traducción del BI atribuida a Pseudo Rufino de Aquilea ${ }^{4}$ (Tyrannius Rufinus Aquileiensis), cuya vida se fija en los años 345-411.

* Elaborado dentro del Proyecto FFI2017-82850-R del Ministerio español de Economía, Industria y Competitividad.

${ }^{1}$ Para la presencia y utilización de Josefo en la GE, Lida de Malkiel, 1959; Malkiel, 1968-1969; Rico, 1972; Eisenberg, 1973; Feldman, 1984 (revisa el texto, las traducciones, la denominación Josippus, su vida, la paráfrasis de la Biblia, el historiador, sus fuentes, las religiones, arqueología, vocabulario y estilo, influencias hasta el siglo XX -con un apartado dedicado a la literatura española, 865-868-, y en la literatura contemporánea, más desiderata e índices); Perona, 1989; Fraker, 1996, 177-190, ha señalado problemas de mala traducción del texto de Josefo en la obra alfonsí; Martin, 2000; Avenoza, 2003; Nieto Ibáñez, 2004; Almeida-Trujillo, 2008; Puerto Benito, 2008; López Férez, 2014; Almeida, 2015; Bautista, 2017; etc.

${ }^{2}$ Son útiles las bibliografías ofrecidas en http://www.josephus.org/books.htm y https://www.oxfordbibliographies.com/view/document/obo-9780199840731/obo-9780199840731-0049.xml.

${ }^{3}$ Es muy conveniente consultar el The Latin Josephus Project, indicado en la Bibliografía. Para las traducciones latinas de Josefo, véanse Levenson - Martin, 2016a y 2016 b.

${ }^{4}$ Véase Thuval, 2019. 
La versión, bastante literal, realizada en el siglo IV, no cuenta, hasta la fecha, con una edición crítica. Posteriormente, Casiodoro encargó en el siglo v la versión de $A I$ y del $A p$., realizadas por sus colaboradores en el monasterio de Vivarium 5 .

3. La General Estoria, denominada también, en la Primera parte, General e Grand Estoria, o, simplemente, Estoria, redactada entre 1272 y 1284, año de la muerte del rey sabio, pretendía abarcar la historia de la humanidad desde la creación del mundo hasta la época del monarca. Aunque tan magno empeño no pudo cumplirse, pues llegó sólo hasta los años previos al nacimiento de Cristo, lo que nos ha llegado constituye un precioso legado de enorme importancia, vastedad y pluralidad. La obra enriquece los datos traducidos y sacados de la Biblia con los ofrecidos por los escritores más relevantes de la Antigüedad, entre los que figuran en lugar preeminente numerosos latinos y algunos griegos. Los materiales son de muy diversa procedencia, por lo que se tuvo que hacer un gran esfuerzo para traducirlos ${ }^{6}$, y, en todo caso, armonizarlos y conseguir un estilo coherente y relativamente unitario. Como el rey confiesa en algunas ocasiones, la General Estoria es una labor de equipo que pasó por diversas revisiones, entre las que destaca la llevada a cabo por él mismo, muy preocupado por la corrección del castellano ${ }^{7}$. Aun así, las digresiones y paréntesis no son pocos, y, sobre todo, las contradicciones respecto a las versiones seguidas acerca de un mismo suceso, hasta tal punto que, a veces, lo que se afirma en un lugar se pone en duda o se niega en otro ${ }^{8}$. La General Estoria se inserta en el movimiento cultural europeo que siguió al IV Concilio de Letrán (1215-1216). Uno de los efectos del mismo fue la versión

${ }^{5}$ Se conocen 171 manuscritos de dicha traducción. El texto de los primeros cinco libros fue publicado en edición crítica por F. Blatt. Sobre la versión latina de las $A I$ manejadas por los redactores de la $G E$, véanse más información en la nota 17.

${ }^{6}$ Pym, 1996.

${ }^{7}$ Cf., entre otros, Solalinde, 1915; Menéndez Pidal, 1951. Respecto a la intervención real en la composición de la General Estoria es relevante un pasaje como el siguiente (GE I.16.14): «assí como dixiemos nós muchas vezes el rey faze un libro non por quel él escriva con sus manos, mas porque compone las razones d'él e las emienda e yegua e endereça e muestra la manera de cómo se deven fazer, e desí escrívelas qui él manda, peró dezimos por esta razón que el rey faze el libro. Otrossí cuando dezimos el rey faze un palacio o alguna obra non es dicho porque lo él fiziesse con sus manos, mas porquel mandó fazer e dio las cosas que fueron mester pora ello; e qui esto cumple aquel á nombre que faze la obra, e nós assí veo que usamos de lo decir».

${ }^{8}$ Fernández Ordóñez, 1999, 105-126, demuestra que las escuelas alfonsíes trabajaron desde 1250 hasta la muerte del rey sabio; que hacia 1270 se gestó el proyecto concreto de redactar tanto la Estoria de España como la General Estoria; y que las dos obras recurren a las mismas traducciones de las fuentes (entre ellas, Plinio, Ovidio, Lucano, Pompeyo Trogo, Justino, Orosio, Eusebio-Jerónimo, Sigeberto de Gembloux, Lucas de Tuy, Hugucio, Jiménez de Rada, etc.). De la misma estudiosa, véanse, entre otros, 1989, 1992. Señalo unos pocos estudios sobre la $G E$, entre muchos: Lida de Malkiel, 1958-1959, 1959-1960; López Férez, 2014. 
de la Biblia al castellano entre los años 1250-1280, y al francés, algo más tarde. La General Estoria contiene la segunda traducción castellana ${ }^{10}$, no literal ${ }^{11}$, de la Vulgata latina de San Jerónimo ${ }^{12}$. Unas décadas antes, se había redactado la Biblia prealfonsina, que, en dos códices, se conserva en la Biblioteca de El Escorial: abarca parte del Antiguo Testamento y casi todo el Nuevo.

Por mi parte me limitaré en este trabajo a la Primera parte de la $G E$, precisamente la que, con respecto a la Biblia, abarca los hechos contenidos en el Pentateuco: desde la creación del mundo hasta la muerte de Moisés. En esta parte de la magna obra alfonsí, los redactores recurrieron con gran frecuencia a las $A I$ de Josefo.

4. Hacia mediados del XX Lida de Malkiel ${ }^{13}$ dedicó un excelente estudio a la presencia e importancia de Josefo en la GE. Por su utilidad resumo los puntos esenciales de dicha aportación.

4.1. La investigadora se detiene, en primer lugar, en la influencia de Josefo dentro de la literatura castellana desde el siglo XII; examina la $G E$ como Biblia historial, pues la obra fue recogiendo noticias referentes a otros pueblos, siguiendo el método de Eusebio y Jerónimo, y, por eso, la GE gusta tanto de la Historia scholastica de Pedro Coméstor ${ }^{14}$. De esa orientación de la $G E$, viene también la importancia dada en ella a Josefo, quien en sus $A I$ había unido la historia judía con la de otros pueblos. El historiador judío, en dicha obra, libros 1-13, aborda el contenido histórico de la Biblia; y en los libros últimos, 14-20, expone una datación según los calendarios judío, griego y macedónico, lo que le convierte en un modelo para Eusebio y Jerónimo. En este sentido conviene subrayar que incluso Jerónimo, adverso a la Biblia como literatura, elogia a Josefo, afirmando que se le apreciaba en alto grado y que su fama había llegado hasta sus propios días ${ }^{15}$.

${ }^{9}$ Guyart des Moulins publicó una versión de la Biblia en francés antiguo a finales del siglo XIII (1297). Se trata de la Bible historiale, que parte, no sólo de la Vulgata, sino también de la paráfrasis latina realizada por Pedro Coméstor, hacia 1170, en su Historia Scholastica. Acerca de la GE como Biblia historial, Morreale, 1982.

${ }^{10}$ Respecto a las peculiaridades de la traducción en la GE, Rubio Tovar, 2014.

${ }^{11}$ La General Estoria traduce y comenta casi todos los libros canónicos de la Biblia.

${ }^{12}$ Hecha a partir del texto hebreo, no de la versión griega de los Setenta. Fernández Ordónéz, "El taller historiográfico...», 119, subraya que la traducción de la Biblia se comentó, entre otras fuentes, con ayuda de la citada obra de Coméstor. Éste es mencionado 633 veces en la parte que revisamos.

${ }^{13}$ Lida de Malkiel, 1959. Léase también su aportación de 1972. Importante es asimismo el trabajo de su esposo, Malkiel, 1968-1969.

${ }^{14}$ La Historia Scholastica (recogida en la Patrología latina de Migne,198, 1053-1644) conoció un éxito inmediato y enorme desde su terminación hacia el 1170, cuando circulaban ya 25 manuscritos de la misma. De la obra se conocen al menos 800 manuscritos, de los que se hicieron miles de copias para uso de los estudiantes. La editio princeps apareció en Ausburgo, 1473.

${ }^{15}$ Jerónimo, de viris illustribus 13. 
4.2. La $G E$ acude, en algún pasaje a Josefo porque este «cuenta más», y se detiene en aspectos no tratados en la Biblia ni en otros comentaristas de la misma. Otro asunto muy relevante es que Josefo juzgaba auténtica la tradición oral, incorporándola en su historia (Lida, 1959: 168).

4.3. Lida examina algún ejemplo de amplificación de la $G E$ a la vista del relato bíblico y la explicación de Josefo: concretamente el asunto de cómo Esaú se casó con las dos mujeres cananeas. La estudiosa señala que es el plano didáctico, la enseñanza moral, lo que le interesa ante todo a Josefo y que, en ese punto, le sucede lo mismo a la $G E$.

4.4. Unas veces la $G E$ se empeña en poner de acuerdo a Josefo con la Biblia y con la Historia scholastica; otras veces, se aparta de la interpretación de Josefo, pues este no recoge ciertos milagros que la $G E$ sí ofrece; en ocasiones acepta las interpretaciones racionalistas de Josefo, pero otras, no; asimismo, la obra alfonsí incorpora, en determinados lugares, pasajes o asuntos omitidos por Josefo, pues iban contra el monoteísmo judío. Así, la historia del becerro, los querubines, el altar y bosque de Baal, el efod ${ }^{16}$ de Gedeón. De otro lado, si Josefo, en ciertos lugares, atenúa los datos de la Biblia, la $G E$, unas veces lo sigue, pero otras, no.

4.5. La $G E$ sabe que al seguir a Josefo tenía a su lado toda la tradición historiográfica occidental, pero, no obstante, elige o amplía el relato mediante las obras arábigas y las de otros numerosos comentaristas.

4.6. La $G E$ sigue la versión latina de las $A I$, la realizada quizá en el círculo de Jerónimo, pero atribuida al Pseudo-Rufino de Aquilea ${ }^{17}$.

4.7. Respecto a la comprobación de las fuentes, leemos en el texto alfonsí: «catamos nós el Josepho e fallamos que es assí» ${ }^{18}$. Ahora bien, los redactores no

${ }^{16}$ Con las joyas tomadas a los vencidos, Gedeón se hizo elaborar un efod. No hay tampoco acuerdo entre los expertos en relación con dicho objeto: unos dicen que se trataba de todo un atuendo sacerdotal con sus joyas y adornos; otros, que se hace referencia a una tabla o instrumentos para hacer consultas a Yahveh. Sin embargo, el citado elemento llevó nuevamente a la idolatría a los israelitas. Según el $D L E$, el efod es una vestidura de lino fino, corta y sin mangas, más o menos lujosa, que se ponen los sacerdotes del judaísmo sobre todas las otras y les cubre especialmente las espaldas.

${ }^{17}$ Lida, 1959, 172, cree que se trata de la realizada por orden de Casiodoro en el siglo VI. La estudiosa revisa una serie de lugares donde la indicada versión latina ha dado lugar a confusiones tanto en la Historia scholastica como en la GE. Parte Lida de su propia versión de la traducción inglesa de Thackeray et alii (la edición bilingüe griego-inglesa de la Loeb), y de la edición del Pseudo-Rufino realizada por Girolamo Squarzafico, Venecia, 1486 (Véase Bibliografía).

${ }^{18}$ GE I.1.1. 
"cataron», ni se percataron del trueque que había hecho Rabano ${ }^{19}$ en su lectura de la Biblia, cuando, al tratar el origen de la sabiduría, puso Jubal en vez de Set, a quien se la había atribuido Josefo.

4.8. La $G E$ tiene a Josefo casi por un santo, pues cabe deducirlo de frases alfonsíes como "Josefo e los otros sanctos padres»"

5. Por mi lado destacaré algunos puntos que me han parecido dignos de señalar en la parte estudiada de la $G E$. Con respecto a mi objetivo, he contado 743 apariciones del antropónimo "Josefo» en la Primera parte de la GE. Tómense, pues, los datos como provisionales hasta conocer los resultados de toda la obra.

5.1. Algunos asuntos los trata Josefo, pero no la Biblia, y llaman la atención en la $G E$, que los recoge. Así el interés de los hijos de Set por la astrología ${ }^{21}$.

5.2. A su vez, la $G E$ se interesa, en ocasiones, por aspectos que no trata Josefo. Tal sucede con el asunto de los 37 hijos que Lamec tuvo con sus dos mujeres ${ }^{22}$.

5.3. Hay también puntos que la $G E$ adjudica a Josefo, pero que este no dice o lo afirma de otra manera. Veamos dos ejemplos. En el primero leemos:

De los otros seis fijos de Jafet fallamos lo que avemos dicho, mas de Tubal nin Moisén nin Josefo non veemos que fablassen señaladamientre de puebla que él fiziesse nin los suyos, si non que Moisén llama su nombre Tubal, e que Josefo le dize Jobel, e más que él pobló los jebelos, e que los jebelos son los iberos, e iberos dizen en latín por españoles ${ }^{23}$.

En realidad, Josefo ${ }^{24}$ escribe que «Teobelo funda a los teobelos, que ahora se llaman iberos» (katoikizei dè kaì Theobélous Theóbēlos, hoitines en toîs nûn Íbēreš kaloûntai). Pero, por si fuera poco, la $G E$ añade, además, que ese nombre «iberos»

${ }^{19}$ Puede acudirse a Rabano Mauro (Rabanus Maurus, Commentariorum In Genesim Libri Quatuor, en la Patrologia latina, vol. 107, col. 508. Con referencia a Jubal, leemos: De hoc Josephus historiographus Judaeorum ita refert: Jubal autem, inquit, musicam coluit et psalterim citharamque laudavit).

${ }^{20} G E$ I.11.50; I.17.2.

${ }^{21}$ Cf. $A I 1.68-9$ y véase $G E$ I.1.27. Es relevante el interés de la $G E$ por el conocimiento de la astrología y los «estrelleros». Sobre el particular léase Fernández Ordóñez, 1999.

${ }^{22} G E$ I.1.14.

${ }^{23} G E$ I.3.1. Véase además otra secuencia (I.3.2). «Jobel pobló los jobelos. E éstos, segund diz Josefo, son los que agora an nombre iberos, que somos los españoles».

${ }^{24} A I 1.124-125$.

${ }^{25}$ Pero, en realidad, esos iberos no son los de Iberia (luego, Hispania), sino un pueblo del Cáucaso. 
era del latín, equivalente a «españoles», afirmación donde se contienen varios errores acumulativos.

Otro ejemplo:

E fue por ventura, segund dize Josefo, porque las non sopieron nin coñocieron los griegos nin les mudaron los nombres en la sazón que los mudavan a las otras gentes e tierras. Peró dize Josefo que por apostura e fermosura de los escritos e a deleit de los que los leyén mudaron los griegos los nombres a las tierras e a las yentes ${ }^{26}$.

Lo que dice realmente Josefo $(A I 1.121)$ es que los griegos cambiaron los nombres, porque, cuando tomaron después el poder, lograron la fama del pasado, embelleciendo a los pueblos con nombres de acuerdo con lo que era entendido por ellos e imponiéndoles una forma de gobierno como si fueran descendientes de ellos.

5.4. Una constante de la $G E$ es informar de cómo fue la transmisión de los saberes desde la Antigüedad, su paso por Grecia y Roma y luego entre «los latinos». Así, sin reparos cronológicos, se nos dice que Josefo afirma que los conocimientos del cuadrivio empezaron en Caldea:

E maguer que nós avemos dicho ya segund Josefo que los saberes del cuadruvio tomaron el comienço en Caldea e d'allí vinieron a Egipto e a Grecia, esto dezimos que es verdad cuanto al su comienço, mas d'otra guisa en Grecia fueron apurados e acabados e puestos en certedumbre ${ }^{27}$.

El texto alfonsí había dicho antes que el padre de Abrahán era entendido en esos saberes, pero que lo fue de modo especial Abrahán:

Cuenta Josefo en el ochavo capítulo del primero libro de la estoria de la Antigüedat de los judíos palabras ya cuanto oscuras d'esta razón de Abraham, e peró muy buenas, e son éstas en que diz assí. Abraham fue por sí omne muy entendudo en todas cosas e sabio en todas aquellas que oyera e aprendiera de los otros sabios, e en todas aquellas de que omne algo podrié asmar, e sabio otrossí e apercebudo de las cosas que avién de venir. E entendiélo por las ciencias del cuadrivio, dond era él muy grand senor, e por ende diz que fue mayor de todos los otros de la su sazón por virtud de la sapiencia que aviées

Como he adelantado, la $G E$ también lo afirma de Taré, el padre de Abrahán:

E él trabajava de los saberes del cuadrivio, e sobre todo del saber de las estrellas. E esto assí fallamos que lo fizieron, peró que unos más e otros menos por la mayor parte todos los padres de la liña tan bien en esta segunda edad como en la primera, assí

\footnotetext{
${ }^{26} G E$ I.3.1.

${ }^{27} G E$ I.6.28.

${ }^{28} G E$ I.4.8.
} 
como vos contamos en las razones de la primera edad que lo cuenta d'ellos Josefo. Entre todas las otras tierras los de Caldea se trabajavan del saber de las estrellas más que otra yente a aquella sazón. E a Tare plogó d’ello mucho, e fincó allí de morada con su compaña ${ }^{29}$.

Finalmente, la $G E$, refiriéndose al tiempo en que Abrahán vivía en Ur (Caldea), añade:

E fasta esta sazón morara Abraham en tierra de Caldea e de Mesopotamia, e estudiara ý en los saberes del arte del arismética, que es saber de cuenta, e de la geometría, que muestra el saber del mesurar e de medir las cosas del cielo. E era Abraham muy sabio d'estos e d'otros saberes más que cuantos otros maestros avié entre todos los caldeos $^{30}$.

Además, la $G E$ añade que el citado habló de la existencia de un solo dios: «E Josefo en razón de pruevas d'esto que dixo Abraham diz en el seteno capítulo del primero libro de la Antigüedat de los judíos, e trae por testigos los sabios caldeos que fablaron del saber de Abraham ${ }^{31}$. Pues bien, si consultamos a Josefo veremos que este no dice nada de los saberes de Taré, y, a propósito de Abrahán, indica que, precisamente, viviendo en Caldea, y por haber hablado en tales términos de $\operatorname{dios}^{32}$, se vio obligado a salir hacia Cananea, porque se habían levantado contra él los caldeos y los demás mesopotámicos ${ }^{33}$.

5.5. Nos detendremos en varios asuntos de los que la $G E$ refiere que constan en Josefo, cuando o no figuran en este, o aparecen pero de forma bastante distinta. Así, con referencia a la estancia de Abrahán en Egipto, leemos en la GE:

E començó Abraham a enseñar allí a las yentes e tener escuelas de los saberes que dixiemos del arte de la astrología, e de la arismética e de la geometría, así como fazié en Caldea e en Cananea. E diz Josefo que se trabajava Abraham d'esto por estas cuatro razones: la una porque oviessen de qué bevir él e sus compañas e passar bien mal tiempo; la otra por oír los clérigos sabios d'allí e aprender d'ellos qué dizién de Dios; la tercera que si fallasse algunos que creyessen en Dios mejor e más sanamientre que de como él creyé, que toviesse él aquella carrera; la cuarta que si non fallasse en Egipto qui croviesse de Dios tan bien como él que les mostrasse él la verdad e gela fiziesse entender e creer. E maguer que Abraham fincó poco en aquella tierra tanto enseñava bien e agudamientre que de estonces aprendieron los d'allí las artes liberales e las sopieron por Abraham, qui las decogió en Caldea ó fueron primero e las enseñó

\footnotetext{
${ }^{29} G E$ I.4.2.

${ }^{30} G E$ I.4.32.

${ }^{31} G E$ I.4.14.

${ }^{32} A I 1.154-155$.

${ }^{33} A I 1.157$.
} 
él en Egipto; e por esso dizen Josefo e maestre Godofré que estos saberes primero fueron en Caldea que en otro logar, e d'allí los ovieron los de Egipto, e de Egipto vinieron a los griegos, e de los griegos a los de Roma, e de Roma a África o a Francia. E por esta razón dixo otrossí Josefo que el comienço del saber e de los reyes e de las batallas que de oriente se levantó primero, e en occidente se deve acabar. E que esto es segund que anda el sol. E por estos saberes que avemos dichos que enseñava Abraham acogiénse a él las yentes e pagávanse d'él, e dávanle por ello todas las cosas que avién mester él e sus compañas ${ }^{34}$.

Frente a esa digresión amplificada, si acudimos a Josefo ${ }^{35}$, nos informamos simplemente de que Abrahán, cuando estaba con Sara en Egipto, les enseñó a los egipcios aritmética y astronomía, saberes que ellos ignoraban hasta entonces, y que pasaron de Caldea a Egipto y de aquí a los griegos.

Otro ejemplo lo encontramos cuando se habla de cómo Labán y Jacob hicieron las paces:

Essora luego empós estas palabras tomó Jacob una piedra e alçola allí en señal d'este fecho en aquel mont ó dixiemos que fincaran sus tiendas éll e Labam, e mandó a los sós aduzir otras, e ellos ayuntaron tantas que d'ella fizieron montón. E segund cuenta Josefo, era pilar alto a semejança de altar, e llamól Labam ell otero del testigo, e Jacob el montón del testimonio, cadaúno segund su lenguaje $\mathrm{e}^{36}$.

Nada hay en el pasaje de Josefo ${ }^{37}$ que apoye los dos nombres dados al montón de piedras (en griego se trata de una columna o pilar (stélēe que tendría la forma de altar), y menos que suegro y yerno hablaran lenguas distintas, o, al menos, que le hubieran puesto dos nombres distintos a dicho altar.

Otrosí lo hallamos cuando, tras despedirse de Labán, Jacob volvía con su familia hacia Canaán:

Jacob, de quien avemos dicho cuando se partió de su suegro Labam, ívase pora Cananea assí como avié començado, e apareciéronle en la carrera muchos ángeles de Dios, e prometiéronle mucho bien, segund cuenta Josefo ${ }^{38}$.

En el historiador judío leemos ${ }^{39}$ que, Jacob, mientras hacía ese viaje, tuvo visiones (phantásmata) que daban buenas esperanzas, pero nada encontramos respecto a la presencia de «ángeles de Dios» ${ }^{40}$.

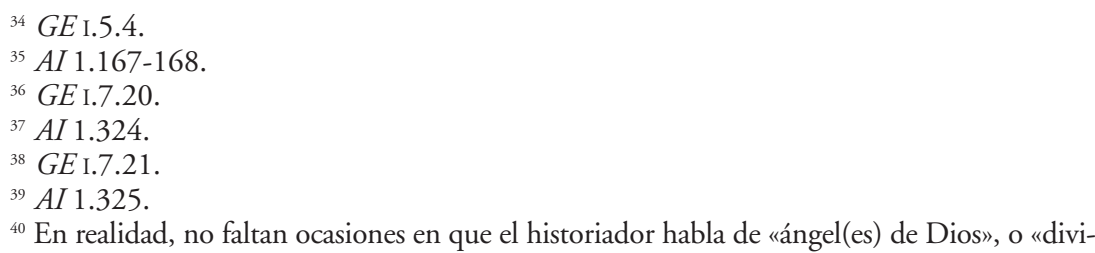
no». Cf. $A I 1.73,189,198,219,332,333$, etc. 
Veamos dos secuencias más. Según la $G E$, parece desprenderse de Josefo que, cuando los hermanos de José fueron a Egipto a buscar trigo, este hablaba con ellos mediante traductor:

Josep cuando les estas razones oyó quiso saber aún más por las palabras d'ellos mismos qué voluntad trayén, e maguer que les él non respondié por el su lenguage peró muy bien les entendié, ca en aquel lenguage se criara él en casa de su padre con ellos e non lo olvidara, ca era omne de buena memoria, e mandó al trujamán responder d'esta manera a las razones que ellos dixieron, segund cuenta Josefo ${ }^{41}$.

\section{La $G E$ insiste en ese punto:}

Aquella ora començaron ellos todos a dezir d'ello entre sí cuedando que lo non entendié Josep porque fablava con ellos por trujamán, e falláronse todos por muy culpados a las palabras de Rubén su hermano, e colgaron todos a tierra las cabeças, assí como sabidores del fecho cómo fuera, e tómaronse cadaúnos a emer e solloçar, e lloravan muy grievemientre e dizién ${ }^{42}$.

Ahora bien, en Josefo, José y sus hermanos conversan, sin problema alguno, desde el primer momento, y sólo, tras el primer encuentro, cuando José decidiera que uno de los hermanos se quedara en palacio como rehén hasta que trajeran a Benjamín, los otros hablaron entre sí «pensado que José no comprendería su propia conversación» (o "habla», como modo de hablar, o incluso «lengua»: ouch hègoúmenoi tòn Iôsēon glôssēest3 tês autôn siniénai $)^{44}$.

Y, por último, respecto al nombre de Moisés:

E por aquel avenimiento que acaeciera assí a doña Termut quel fallara en el agua llamól Moisés, porque mois en el lenguage de Egipto, segund cuenta Josefo, tanto quiere dezir en el nuestro de Castiella como agua, e la es como librado. E ayuntó estas dos palabras de su lenguage mois e es e fizo d'ellas este nombre Moisés, que muestra segund esto tanto como librado de muert por agua, e aun librado dell agua o de la muert del agua ó pudiera morir e perderse si aquel acorro non fuesse $e^{45}$.

${ }^{41} G E$ I.8.18.

${ }^{42} G E$ I.8.19.

${ }_{3}^{43}$ En $A I$ hay varios pasajes en que el historiador distingue claramente entre la "lengua" de los hebreos y la propia de los griegos: así, de la primera 1.34.333, 3.135; etc.; de la segunda, 1.284, 3.144, etc. En la frase que estamos viendo hemos de suponer que José hablaba «egipcio». Josefo, en cambio, que, en varias ocasiones, menciona la «lengua de los hebreos»y, en algunas, la «de los griegos», sólo en un lugar ( $A p$. 2.21) alude a la de los egipcios. También apunta en dos textos a la de «los romanos».

${ }_{44} A I 2.108$. En ningún momento de las sucesivas conversaciones tenemos el término hermēneús, «intérprete», que, conocido en griego desde Píndaro y Esquilo, usa también Josefo en dicha obra: AI 3.88, 12.107.108, 18.197.

${ }^{45}$ GE I.11.21-23. 
Josefo ${ }^{46}$ nos dice escuetamente que (sc. la princesa) le puso el nombre en relación con lo sucedido por haber caído el niño en el río, pues «los egipcios llaman al agua môu, y esês, a los salvados» (Recordemos que el nominativo de Moisés en griego es Mōusês).

5.6. Recojo ahora tres ejemplos de la llamada en retórica latina amplificatio, que, para muchos, comprende tanto la ampliación de lo tratado como la importancia que a dicho asunto se le otorga en el relato. En primer lugar el relato sobre las causas de la larga vida de los antiguos:

Cuenta Josefo sobr'esto en el quinto capítulo que cuando catáremos la vida de los omnes de agora e la vida de los antigos que non tengamos que yerro ninguno á ý en aver vevido tantos años los omnes del primero tiempo. Ca diz que los del primero tiempo muchas razones avién por que visquiessen tanto. Lo uno porque eran religiosos e fazién santa vida como fraires, e eran otrossí mas decerca de la fechura de Dios, e oyeran más palabras de las que Dios dixiera a sos padres e a sos parientes, e las aprendieran ellos e las tenién. Demás que non comién en aquel tiempo si non frutas e yervas, e pocas cosas otras. Mas que aun fasta'l diluvio nin comieran nunca carne nin bevieran vino, nin d'esto nin de ál cosa ninguna a demás por que de lieve enfermassen nunca, que por ello viniessen a muerte nin minguassen nada de su vida. Demás que razona Josefo que aquellos primeros omnes que eran más cerca Dios que se trabajavan de los fechos e de los saberes en que eran las virtudes de las cosas e los nobles e grandes pros, e que era esto el saber de la astrología e de la geometría e de todos los saberes liberales e de los otros. E que en escodriñar las virtudes d'esto que era $\tan$ alta cosa e tan noble e tan provechosa que por aduzirlos a las virtudes puras e ciertas que se non podrié fazer en menos de seiscientos años, e que tanto dura ell año grand. E que por estos bienes de que se trabajavan que les dio Nuestro Señor Dios tan luengas vidas en que lo pudiessen complir. E non solamente Moisén en la Biblia e los ebreos en su ebraigo, mas aun otros sabios muchos de otras tierras e d'otras lenguas, e aun d'otras creencias fallamos que fablan en esta razón, e testiguan que fue assí. Esto tan bien en bárbaros como en griegos ${ }^{47}$.

En Josefo ${ }^{48}$, en resumen, se nos dice que aquellos hombres eran amados por Dios y hechos por Dios mismo, y su alimento era apropiado para hacerles la vida más larga; eran hombres virtuosos, hacían buen uso de sus conocimientos geométricos y astronómicos y por eso pudieron predecir el curso de las estrellas, al haber vivido seiscientos años, que es lo que dura el año grande ${ }^{49}$. El historiador judío añade que

${ }^{46} A I 2.228$.

${ }^{47} G E$ I.2.13. Nótese la acumulación de autores. Además tres citas de Josefo. Advertimos importantes reflexiones sobre la comida y el vino. Nótese, además, la idea sobre la existencia en época tan remota de la astrología y las artes liberales.

${ }^{48}$ AI 1.106-107.

${ }^{49}$ La expresión «año grande» (mégas eniautós) consta en griego desde Hesíodo (Teogonía 799) y era el título de un escrito perdido de Demócrito $(F r$. 33). Las interpretaciones son varias. 
se basa en los autores griegos y bárbaros que habían escrito sobre eso. Ahora bien, nada dice de que hubieran vivido como frailes, ni que comieran sólo yerbas y frutas, sin tomar carne y sin probar el vino.

En segundo lugar, la $G E$ nos explica cómo, tras morir José, empezaron las malas relaciones entre egipcios y hebreos:

E dize Josefo en este logar que los de Egipto eran todos dados a maldad en aquella sazón, los unos a cobdicia, los otros a fornicio, los otros a otros vicios malos de muchas maneras; e los ebreos, que eran de buena vida, e sabidores e engeñosos pora aver algo, e todavía por su lazeria. Onde los egipcianos, que se davan a vicios e a deleit de sus cuerpos, porque sintién a los ebreos mesurados en sus comeres e lo non eran essos egipcianos, e los fornagueros otrossí, porque los sabién de buena vida e guardada d'aquel mal vicio, e querién éstos d'ellos las mugieres, e los que eran cobdiciosos porque los veyén cuerdos e muy ricos e abondados con cobdicia otrossí de levar d'ellos lo que avién, e cadaúnos lo que cobdiciavan segund sus naturas e maldades queriénlos mal todos, e cadaúnos por la su razón, como lo avemos departido, e acogiéronse luego muy de grado al mal que les el rey dizié d'ellos, e otorgárongelo todos. E como son los reyes en los sesos más agudos que los otros omnes asmó aquel rey cuáles serién las cosas por ó los él más podrié apremiar porque menguassen. E segund le enseñaron sus consejeros, tovo en la primera que con lavores de tierra los quebrantarié más que con otra cosa ninguna, porque es lazeria de grand afán contender con tierra ${ }^{50}$.

El historiador judío ${ }^{51}$ presenta, en pocas líneas, a los egipcios como voluptuosos y perezosos para los trabajos, dominados por los demás placeres y sobre todo por la codicia, y añade que, por todo ello, empezaron a estar mal dispuestos hacia los hebreos por envidia respecto a su prosperidad. Insiste en que maltrataron a los israelitas mandándoles hacer todo tipo de trabajos penosos. No se habla, pues, de fornicio, ni de desear a las mujeres hebreas, ni de envidias porque los hebreos comieran con mesura, etc.

Finalmente, a propósito de la expedición de Moisés contra los etíopes que habían invadido Egipto (suceso que no consta en la Biblia), la $G E$ se detiene en la edad del citado:

e veno a edad acabada, que segund dize Josefo es el tiempo de la mancebía, e segund esto tenemos nós que era Moisén estonces de XXX años, ca al tiempo d'agora la edad de XXX años dan los sabios e los santos padres por edad complida, onde veemos que d'ella judgan los prelados de la santa eglesia de Cristo all clérigo pora ser de ordenar de missa, e otrossí de fazerle abad de abadía acompañada, que es la que á canónigos o monjes, e de fazerle otrossí obispo o aún arçobispo. En que dize Josefo sobre la razón de la edad complida que assí como era Moisén grand cuanto cumplié e fermoso de cuerpo, que assí era otrossí fermoso de bondad e esforçado de coraçón, e que assí

\footnotetext{
${ }^{50} G E$ I.11.4.

${ }^{51}$ AI 2.201-203.
} 
lo mostrava él por sus fechos entre los egipcianos. E tenemos nós que en estas razones que oídes que Josefo el sabio dize de Moisén quel da por de edad acabada, e assí lo dize él mismo en el su libro, que por de edad acabada le da en aquella en que él era, e dezímosvos que esta edad es de XXX años, e por quel avién los egipcianos envidia yl querién mal teniénle todos por bueno, ca assí como la estoria dize al bueno an envidia los malos y quieren mal, ca non a los tales como ellos, e assí fazién los egipcianos a Moisén por esta razón ${ }^{52}$.

El historiador judío ${ }^{53}$, en cambio, nos dice, simplemente, que Moisés «tras haber llegado a la edad visible (eis hélikian phanerán), les dio a los egipcios prueba de su virtud». Digamos que dicha expresión, única en Josefo, sólo tiene un precedente en Aristóteles ( $R h .1379$ a 26), donde la tenemos quizá con otro sentido.

5.7. Veamos ahora dos errores de bulto y una afirmación dudosa. En primer lugar, en torno a las causas de la torre de Babel, Josefo recoge el presagio de la «Sibila»" sin más explicaciones, pero en $G E$ se habla de "Sevilla Cassandra " ${ }^{55}$.

En segundo, durante la salida de Egipto, los hebreos llegaron a un sitio que después se llamaría Babilonia, fundado por Cambises cuando subyugó Egipto ${ }^{56}$ :

E dizen Josefo e maestre Pedro que después d'esto aquel rey de Etiopia que ovo nombre Cambises vino a Egipto, e destruxo toda la tierra e pobló aquella cibdad de cabo, e cuando la poblava esse rey Cambises pusol nombre Babilón, e ésta es a la que dizen Babiloña la de Egipto. E maguer que era yerma estonces, poblada dizen que es agora ${ }^{57}$.

Y una duda referente a que Josefo vio las dos tablas de la ley: «E cuenta Josefo que él las vío aquellas dos tablas en que Nuestro Señor Dios dio estos diez mandados de la ley a Moisén, e que assí eran escritos en ellas dedentro e defuera como vos contamos que dizen él e los ebreos» ${ }^{58}$. No he encontrado confirmación a este aserto.

${ }^{52} G E$ I.11.35.

${ }^{53} A I 2.238$.

${ }^{54} A I 1.118$. Es ésta la única vez en que el término Sibila (en griego, transcrito, Síbylla) aparece en Josefo. La cita del historiador es recogida por Eusebio dos veces (Praeparatio evangelica 9.15.1; Onomasticon, p.40.16). Las palabras de la citada, en prosa, parecen ser una adaptación de unos versos recogidos en los Oráculos sibilinos (3.97-104).

${ }^{55}$ I.2.21-22. En la literatura griega es rara la asociación Sibila-Casandra: véase Suda, sigma 359. En la $G E$, dicho paralelismo puede haberse debido a la asociación de Casandra con la capacidad de profetizar.

${ }^{56} A I 2.315$.

${ }^{57} G E$ I.12.30. Por lo demás, la GE (I.4.19) habla de Cambises II, rey de Persia; referirse a él como rey de Etiopía, debería entenderse quizá como un título que hubiera adquirido cuando ya había dominado a Egipto ( $G E$ I.11.39). Que dicho monarca tuvo bajo su dominio a Etiopía lo afirma, por ejemplo, Diodoro de Sicilia (1.34.7).

${ }^{58} G E$ I.14.21-22. 
5.8. Un rasgo relevante de la $G E$ en busca de un testimonio de autoridad respecto a diversos sucesos es recurrir al amontonamiento de menciones de Josefo. Seleccionaré lo más destacado. Lo tenemos a propósito de los hijos de Cam y Jafet $;^{59}$ de que los hebreos se levantan contra Aarón y Moisés ${ }^{60}$; sobre las cubiertas del Tabernáculo ${ }^{61}$; sobre el duelo de los hebreos por la muerte de Moisés; de los años que vivió Moisés ${ }^{62}$; del casamiento de Abrahán con Cetura ${ }^{63}$, y sobre los hijos de Jafet ${ }^{64}$, donde se afirma que los griegos cambiaron los nombres de distintos pueblos; de la adolescencia de José ${ }^{65}$; sobre que José dice quién es ante sus hermanos ${ }^{66}$; del enfrentamiento de Moisés y los suyos contra Sehón, rey de los amorreos ${ }^{67}$; de algunos adornos del Tabernáculo ${ }^{68}$; de las vestimentas hechas para Aarón y sus hijos ${ }^{69}$; sobre que los clérigos quedan librados del ejercicio de armas ${ }^{70}$; de los hijos de Esaú con sus tres mujeres ${ }^{71}$; de cuando Jacob iba a encontrarse de nuevo con su hermano Esaú ${ }^{72}$; de la primera salida de Egipto realizada por Moisés ${ }^{73}$; de los reyes que mandaban cuando Abrahán salió de Egipto ${ }^{74}$.

\section{BIBLIOGRAFÍA AUXILIAR ${ }^{75}$}

\section{FueNTES ESENCIALES.}

\subsection{JOSEFO}

\section{EDICIONES RENACENTISTAS}

ARLenius, A. P. - Gelenius, S. (eds.) (1544): Flavii Josephi opera, Basilea, Hieronymus Froben - N. Episcopius [Editio princeps].

Flavius Josephus (1400-1450): Antiquitates Judaicae, Rufinus AQUILEIENSIS interpres (?), manuscrits [Consultado en gallica.bnf.fr]. Revisada, asimismo, la impresa, junto con otras obras de Josefo,

${ }^{59} G E$ I.2.27-29. Diecisiete menciones.

${ }^{60} G E$ I.23.13-16. Doce citas.

${ }^{61} G E$ I.16. 21-24. Doce referencias.

${ }^{62} G E$ I.29.22-24. Once citas.

${ }^{63} G E$ I.6.16. Once menciones.

${ }^{64} G E$ I.3.1. Nueve citas.

${ }^{65} G E$ I.8.1. Nueve menciones.

${ }^{66} G E$ I.8. 21-23. Nueve citas.

${ }^{67} G E$ I.24.9-11. Ocho citas.

${ }^{68} G E$ I.15.56-58. Ocho alusiones.

${ }^{69} G E$ I.15.78. Siete citas. Con transcripción de nombres del caldeo, hebreo, griego y latín (en un caso se habla de «latin racional»).

${ }^{70} G E$ I.23.19-23. Siete citas en contextos próximos.

${ }^{71} G E$ I.7.44. Siete menciones.

${ }^{72} G E$ I.7.22. Seis citas.

${ }^{73} G E$ I.11.35. Seis citas.

${ }^{74} G E$ I.5.18-19 Seis menciones. Con una referencia histórica al emperador Teodosio.

${ }^{75}$ Aparte de esta bibliografía selecta las notas recogen otros estudios. 
en Venecia, Albertino Vercellese, 1499 [La ofrece la Biblioteca Valenciana, Digital. Es similar a Flavius Josephus, De antiquitate Judaica. De bello Judaico, Trad. Rufinus AQuileiensis, ed. Hieronymus SquarZaficus, Venecia, Albertinus Vercellensis, para [los herederos de] Octavianus Scotus, 23 Oct. 1499. $\mathrm{f}^{\circ}=$ tij00487000, Bodleian Library, University of Oxford].

Flavius Josephus (1481): De antiquitate judaica. De bello judaico. Contra Apionem, Reynaldus DE NovIMAGIO, Venecia [fue la primera vez en que se publicaron juntas las traducciones de esas tres obras].

\subsection{GENERAL ESTORIA}

Texto seguido: P. SÁnchez-Prieto Borja - R. Díaz Moreno - E. Trujillo Belso (2002): Edición de textos alfonsies, en REAL ACADEMIA ESPAÑOLA: Banco de datos (CORDE) [en línea]. Corpus diacrónico del español. <http://www.rae.es> [7 de marzo 2006]: General Estoria. Primera parte [Citamos con tres indicaciones: parte (con romanos), libro y capítulo].

\section{3. ОтRоs.}

BlatT, F. (1958): The Latin Josephus, vol. I. Introduction and Text: The Antiquities, Books I-V (Acta Jutlandica 30.I), Universitetsforlaget, Aarhus - Munksgaard, Copenhague.

The Latin Josephus Project [Con información relevante sobre ediciones y traducciones del historiador judío. Puede verse en https://sites.google.com/site/latinjosephus/antiquities y en $\underline{A W O L-T h e}$ Ancient World Online. Desde el 12 de marzo de 2018, este instrumento, muy recomendado, gratis, con respecto a las Antiquitates Iudaicae, en la misma página, ofrece tres textos: la transcripción latina del manuscrito Bamberg Msc. Class. 78 (de mediados del Ix), el texto griego de Niese (Flavii Iosephi Opera, vol. 1., 1887); y la traducción inglesa de William Whiston, 1737].

$T L G=$ Thesaurus Linguae Graecae $\left(2001^{1}\right)$. University of California. Irvine (California) [en línea. Imprescindible para búsquedas de léxico]. Dicho instrumento informático, para las Antiquitates Iudaicae, ofrece el texto de B. Niese, Flavii Iosephi opera, vols. 1-4, Berlín, Weidmann, 1: 1887; 2: 1885: 3: 1892; 4: 1890 (repr. 1955).

\section{EsTUDIOS}

Almeida Cabrejas, B. (2015): «Índice de nombres propios de la Primera parte de la General Estoria», Lemir 19: 281-360.

Almeida, B. - Trujillo, E. (2008): «Censura y modificación ideológica en la Quinta Parte de la General Estoria de Alfonso X el Sabio", Diálogo de la Lengua 1: 1-14.

AvenozA, G. (2003): «Algunos libros de la biblioteca de Lope García de Salazar», Revista de filología española 83 (1-2): 5-37.

Bautista, F. (2017): «Alfonso X, Bernardo de Brihuega y la General estoria», Atalaya 17 [en línea].

EISENBERG, D. (1973): «The General Estoria: Sources and Source Treatment», Zeitschrift für romanische Philologie 89: 206-227.

Feldman, L. H. (1984): Josephus and Modern Scholarship (1937-1980), W. de Gruyter, Berlín-Nueva York.

Fernández Ordóñez, I. (1989): La Versión Crítica de la Estoria de España en la Historiografia alfonsí. Estudio y Edición (de Pelayo a Ordoño II) [Tesis], Universidad Autónoma de Madrid.

Fernández Ordóñez, I. (1992): Las «Estorias» de Alfonso el Sabio, Istmo, Madrid.

FERnÁNDEZ ORdóNEZ, I. (1999): «El taller historiográfico alfonsí. La Estoria de España y la General Estoria en el marco de las obras promovidas por Alfonso el Sabio», en J. MONTOYA - A. RODRíGUEZ 
(coords.), El Scriptorium alfonsi: de los Libros de Astrología a las Cantigas de Santa María, Fundación Universidad Complutense, Madrid, pp. 105-126.

FraKer, Ch. (1996): The Scope of History: Studies in the Historiography of Alfonso El Sabio, The Michigan University Press, Ann Arbor.

Levenson, D. B. - Martin, Th. R. (2016a): «The Place of the Early Printed Editions of Josephus's Antiquities and War (1470-1534) in the Latin Textual Tradition", en J. BADEN - H. NAJMAN E. TigchelaAr (eds.), Sibyls, Scriptures, and Scrolls: John Collins at Seventy, Brill, LeidenBoston, pp. 765-825.

Levenson, D. B. - MARTin, Th. R. (2016b): «The Ancient Latin Translations of Josephus», en H. Howell Chapman - Z. Rodgers (eds.), A Companion to Josephus, Wiley-Blackwell Malden (MA.)Oxford, pp. 322-344.

Lida de MAlkiel, M. R. (1958-1959): «La General Estoria: notas literarias y filológicas (I)», Romance Philology 12: 111-142.

Lida de Malkiel, M. R. (1959-1960): «La General Estoria: notas literarias y filológicas (II)» Romance Philology 13: 1-30.

Lida de Malkiel, M. R. (1959): "Josefo en la General Estoria», en F. PierCe (ed.), Hispanic Studies in Honour of I. Gonzalez Llubera, Dolphin Book, Oxford, pp. 163-181.

LidA DE MALKIEL, M. R. (1972): «En torno a Josefo y su influencia en la literatura española: precursores e inventores», en Studia Hispanica in honorem R. Lapesa, Cátedra-Seminario Menéndez Pidal, Madrid, I, pp. 5-62.

López Férez, J. A. (2014): «Memoria histórica y tradición clásica en la General Estoria de Alfonso X el Sabio (Primera Parte)», en I. Grifoll - J. AcEBrón - F. SABAtÉ (eds.), Cartografies de l’ànima: identitat, memòria i escriptura, Pagès editors, Lleida, pp. 173-200.

Malkiel, Y. (1968-69): «El libro infinido de María Rosa Lida de Malkiel: Josefo y su influencia en la literatura española», Filología [Buenos Aires] 13: 205-226.

MARTIN, G. (2000): «El modelo historiográfico alfonsí», en G. MARTIN (ed.), La historia alfonsí: el modelo y sus destinos (siglos XIII-XV), Casa de Velázquez, Madrid, pp. 9-40.

Menéndez Pidal, G. (1951): «Cómo trabajaron las escuelas alfonsíes», Nueva Revista de Filología Hispánica 4: 363-380.

Morreale, M. (1982): «La General Estoria de Alfonso X como Biblia», en G. Bellini (ed.), Actas VII AIH (Congreso de la Asociación internacional de Hispanistas. Venecia, 1980), Bulzoni editore, Roma, pp. 767-773.

Nieto IbÁN̄EZ, J. M. (2004): «Flavio Josefo en los Antiquitatum Iudaicarum libri IX de Arias Montano», en J. F. Domínguez Domínguez (coord.), Humanae litterae. Estudios de humanismo y tradición clásica en homenaje al profesor Gaspar Morocho Gayo, Universidad de León, Secretariado de Publicaciones y Medios Audiovisuales, León, pp. 367-380.

Puerto Benito, J. J. (2008): The Heroides in Alfonso X's General Estoria: translation, adaptation, use and interpretation of a classical work in a thirteenth-century Iberian History of the world [Tesis], Lexington, Kentucky.

PyM, A. (1996): «The Price of Alfonso's Wisdom: Nationalist Translation Policy in Thirteenth Century Castile», en R. Ellis - R. TIXIER (eds.), The Medieval Translator. Traduire au Moyen Âge. Proceedings of the International Conference of Conques (26-29 july 1993), Lovaina la Nueva, Brepols, pp. 448-467.

Rico, F. (1972): Alfonso el Sabio y la General estoria: tres lecciones, Ariel, Barcelona. 
RUBIO TOVAR, J. (2014): «La traducción en la General Estoria», en La cultura en la Europa del siglo XIII. Emisión, intermediación, audiencia, Actas XL semana de estudios medievales. 2013, Gobierno de Navarra. Departamento de Cultura, Turismo y Relaciones Institucionales, Pamplona, pp. 247-284.

Solalinde, A. G. (1915): «Intervención de Alfonso X en la redacción de sus obras”, Revista de Filología española 2: 283-288.

Thuval, M. (2019): «Flavius Josephus», en A. KuliK - G. BocCaCcini - L. DiTommaso - D. HamidoVIC - M. E. STONE (eds.), A Guide to Early Jewish Texts and Traditions in Christian Transmission, Oxford University Press, Oxford, pp. 281-299. 
